\title{
Voting Behaviour in the European Parliament and Economic Governance Reform: Does Nationality Matter?
}

\author{
Elisa Cencig $^{1} \cdot$ Laura Sabani $^{2}$
}

(C) The Author(s) 2017. This article is an open access publication

\begin{abstract}
This paper analyses MEPs' voting behaviour on all regulations and directives forming the Six-Pack and the Two-Pack together with the key vote required to establish the European Stability Mechanism (ESM). Whereas scholarly work has traditionally showed MEPs voting behaviour to be primarily driven by ideology (more specifically, by the MEP's party group affiliation), we expect to find MEPs' national origins to play a counterbalancing role and - at least partially - weaken intra-party position on key economic governance matters, where a conflict of interest might exist between creditor and debtor member countries. Findings confirm that national interests and country-level economic variables can predict MEPs' votes in a considerable number of cases, opening new avenues for future research on territorial cleavages in the European Parliament.
\end{abstract}

Keywords European Union · crisis management · econometrics · economics

JEL Codes $\mathrm{P} 16 \cdot \mathrm{C} 25 \cdot \mathrm{F} 53 \cdot \mathrm{H} 12$

This paper was presented at the European Economics and Finance Society conference in Amsterdam, June 2016, and at the Annual Meeting of the Italian Economists Society (Società Italiana Economisti), in Milan, October 2016. We thank all participants in the panels for their useful comments.

Elisa Cencig

e.cencig@1se.ac.uk

$\triangle$ Laura Sabani

1sabani@unifi.it

1 Department of Government, London School of Economics, Houghton Street, London WC2A 2AE, UK

2 DISEI, University of Florence, Via delle Pandette 21, 50129 Florence, Italy 


\section{Introduction}

The economic and financial crisis had profound consequences not only for the economies of EU's Member States, some of which are still far from complete recovery, but also for the architecture of the Economic and Monetary Union. A number of measures has been taken at $\mathrm{EU}$ level to reinforce the coordination of economic governance in the bloc and enhance regulation of the financial sector, aiming to better cope with similar crisis scenarios in the future. Most of the policy response, following the agenda-setting impulse by the European Council, was enacted through EU legislation, thereby requiring approval from the European Parliament.

The aim of this paper is to analyse MEPs' voting behaviour on a key number of final legislative votes in the area of economic governance reform. Elected parliamentarians, when deciding whether to vote for or against legislation, must balance the wishes of the overall electorate, those of their specific constituencies within it, pressure from party leaders and their own peculiar ideological leanings (Levitt 1996). While researchers tend to agree that ideological inclination - under the form of party group affiliation - is the primary determinant of vote choice for Members of the European Parliament, these legislators are also agents with multiple principals, trying to balance out the pressure coming from various sources. One of the potential determinants of vote choice is an MEP's nationality. Whereas several studies have confirmed the weakness of nationality as such a factor influencing voting behaviour in the EP, we expect this established tenet not to hold in the case of fiscal policy. As opposed to policy areas where EU competences are solid and have long been established, fiscal integration is a sector close to the fortress of national sovereignty and the hugely symbolic 'power of the purse'. EU integration in this area, in other words, potentially has much higher consequences on a state's capability to tax and spend, severely impairing its fiscal autonomy. If consequences for their own Member State are so crucial, we expect MEPs' specific constituency (their nation state of origin) to play a much higher role than usual on legislation related to fiscal discipline. This is particularly the case when fiscal restrictions might have a differential impact on Member States due to their varying pre-existing fiscal position and the intensity of the economic crisis which has hit them. While our research does not overall challenge the primary finding that party affiliation is the main determinant of vote choice in the EP (like in any other legislature), we aim to better disentangle the different components of vote choice. This analysis is all the more crucial when legislative votes refer to measures having differential impacts on the different countries MEPs come from.

As far as economic governance is concerned, all regulations and directives forming the Six-Pack and the Two-Pack are analysed, together with the key vote required to establish the European Stability Mechanism (ESM). ${ }^{1}$ Whereas scholarly work has traditionally showed MEPs voting behaviour to be primarily driven by ideology (more specifically, by the MEP's party group affiliation), we expect to find MEPs' national origins to play a counterbalancing role and - at least partially - weaken intra-party position on key fiscal integration matters, where a conflict of interest might exist

\footnotetext{
${ }^{1}$ Financial regulation reform, arguably a similar policy area, is left aside due to the large consensus among MEPs surrounding the regulatory measures taken in this field.
} 
between creditor and debtor member countries. We hypothesise the potential presence of a tension between EP party affiliation and national identity with regard to economic governance issues, because national sovereignty plays a crucial role in the fiscal space domain. Sovereign states are driven by their own interests with regard to fiscal policy, since their preferred policies are deeply linked to their specific economic conditions, and European legislation constraining the possible choices in the fiscal realm has a different impact on Member States' economies, depending on their specific economic cycle conditions. Our research hence aims to identify possible distinctive voting patterns alongside EP political affiliation in this particular policy area. In order to do so, we operationalise these "secondary" factors under the form of economic variables signalling a distress in the MEP's country of origin economic conditions, and we also investigate whether MEPs coming from crisis-ridden (PIIGS) countries display a different voting behaviour than others, anticipating the much higher domestic implications of the EU-imposed fiscal policy reform.

The European Parliament has become a privileged object of analysis for political scientists over the last decades, with waves of scholarly attention closely mirroring the ever-increasing reinforcement of its powers since it was first directly elected in 1979. A vast literature exists on legislative politics in the European Parliament, aimed at the identification of the most significant dimensions shaping political and legislative behaviour in the assembly of the EU. Research on voting behaviour in the EP has become an established field over the years, with the mainstream literature agreeing that party group affiliation is the main voting determinant for MEPs. In spite of methodological issues partially undermining these analyses, a consensus exists on an everincreasing level of intra-party cohesion in the EP and on the weakness of national identities in explaining MEPs' voting patterns. Nevertheless, our research builds on some recent qualitative work pointing in the opposite direction and takes a look at voting behaviour on a specific subset of legislative votes where national identity is expected to create strong cleavages. Whereas our results do confirm traditional conclusions, we also find that national interests and country-level economic variables can be strong predictors of MEPs' votes. Our models show variables related to these predictors to be statistically significant in a considerable number of cases, opening up new avenues for future research on territorial cleavages in the European Parliament.

This paper is organized as follows. In Section 2 a brief summary of the existing literature on voting behaviour in the European Parliament is presented. In Section 3 recalls the EU-level measures to tackle the crisis by enacting economic governance reform. Section 4 provides information on the database, methodology and hypotheses. Section 5 presents the results of our analysis and Section 6 contains some concluding remarks.

\section{Related Literature}

Research on voting behaviour within the European Parliament builds upon previous work on the US Congress, comprising seminal articles that tried to disentangle the different determinants of voting dynamics among elected representatives of the US population. For example, Levitt (1996) considers several possible factors, namely personal preferences, the constituency's interests, the state electorate preferences and 
national party lines in his study of US senators, and finds out that personal ideological preferences are the strongest determinant of legislators' voting decision.

Since the birth of this institution, most MEPs have been sitting in party groups reflecting traditional European party ideologies, and the minority of legislators sitting in separate "national delegations" has been shrinking over time, in line with the decrease of independent groups in the EP (McElroy 2007, Hix and Høyland 2011). ${ }^{2}$ Therefore, research has focused on the role of party groups in the European Parliament, and several indexes of agreement have been developed to measure intra-party cohesion (Attinà 1990). Intra-party cohesion, signalling consistency in voting behaviour among MEPs from the same ideological area, has been steadily increasing over time. Recent studies reinforce previous findings that EP party groups not only occupy the entire range of the left-right spectrum, but also are clearly distinguishable from one another in policy terms (McElroy and Benoit 2011). Furthermore, scholars showed that party groups, rather than nationality, have played a huge role in coalition formation in the EP from its very establishment (Kreppel and Tsebelis 1999; Kreppel 2000).

A major breakthrough came with the application of the NOMINATE scaling algorithm to roll call vote data from the EP. NOMINATE analyses voting data to place legislators in a multidimensional space, hence identifying the dimensions of conflict in the EP. In view of its supranational character and institutional uniqueness in comparative perspective, the scholarly community indeed had to find out whether traditional domestic dynamics applied to the EP as well. While the classic theories of European integration (intergovernmentalism and neo-functionalism) both see EU politics as centred on the speed of the integration process (more or less integration), these empirical studies confirmed that political competition in this institution revolves around the traditional left-right dimension (Hix 2001). Results clearly indicated that the main dimension of conflict in the European Parliament is the classic left-right divide of democratic politics (accounting for around $85 \%$ of the variation), with the anti/pro-EU integration dimension playing only a minor role. National interests have very little systematic influence on politics in the EP, a result somewhat surprising when thinking of some "state interest" - based theories of EU integration (Hix 2001; Hix et al. 2006).

To sum up, research on directly elected parliaments since 1979 has shown transnational party affiliation to be much more important than national affiliation in determining voting decisions, with party cohesion in the EP steadily increasing over time (Hix 2001; Hix et al. 2006; Hix and Bartolini 2006; Hix and Noury 2009; Ringe 2010). Voting behaviour and coalition formation happen mainly along a single policy dimension in the EP, and this dimension essentially corresponds to the domestic well-known left-right divide (Kreppel 2000; Hix 2001; Hix 2002). However, this scholarly consensus has come under attack on several fronts, with two major substantive and one methodological critique.

Methodologically, this research been criticised because traditionally roll call votes made up only $15-30 \%$ of all votes in the EP, and were likely called for a variety of strategic reasons including the wish to enforce discipline and to signal a particular

\footnotetext{
${ }^{2}$ Bressanelli (2012) investigates the factors behind political group membership in the European Parliament, by fitting a multinomial logit model for political group 'choice' based on the 2009 Euromanifestos data. His findings confirm that ideological compatibility is the most important factor behind transnational affiliation, even if some caution is needed for the 'new', post-communist members.
} 
stance; roll call votes might therefore represent a biased sample of the population of votes (Carrubba et al. 2004; Carrubba et al. 2006; Høyland 2010). Some of these critiques have been addressed by demonstrating the absence of any strategic selection bias between requested and mandated roll call votes, but the possible bias between roll call votes and secret votes has not been explained so far (Hix et al. 2013). This problem will truly disappear only in the future, as roll call votes have been compulsory on all final legislative votes since 2009, and non-binding resolutions in plenary have been subject to the same procedure since March 2014.

A second, substantive critique stems from the observation that MEPs are agents with two principals. In fact, EP legislators are at once members of national parties and affiliated to European party groups; they have multiple sources of affiliation leaving room for a potentially high degree of political conflict. The two different "principals" both require their loyalty: national parties are responsible for the selection of candidates for European elections and EP party groups control the allocation of committee positions, finances, speaking time and other party positions in the European Parliament (Hix et al. 2006). While the positions of one MEP's national party and EP party group normally coincide, there are instances where this is not the case and national delegations cherish minority positions within the respective EP party groups. Hence, countrybased divisions become relevant in cases of conflict between the EP party group position and the national party one. In these cases, research has shown MEPs to be primarily loyal to their national party principals, who are in control of EU elections candidatures (Hix 2002; Cicchi 2013). Nevertheless, national parties and national interests must not be confused and one cannot maintain, basing on these results, that national identities are a strong predictor of voting behaviour in the EP.

Another related critique to RCV research has been moved by scholars underlining that pooling all data hides interesting variance across issue areas and across voting procedures (Gische 2007; Rasmussen 2008; Cicchi 2013). One study on EU trade policy, while confirming that MEPs vote prevalently in line with EP party groups, found that on highly sensitive issues some national delegations vote along their national interests and against the dominant position of their EP party groups (Kang 2013). Another study dealt with foreign policy issues and analysed voting patterns in the EP from 1979 to 2004, confirming the traditional result that EP party lines are the best predictor of voting behaviour (Gische 2007). However, when breaking down votes into more specific sub issues (such as justice or human rights), the author found the country of origin to become a better predictor in some cases, a result which is easily concealed by the pooled, large-n analyses which are standard in the literature. Some recent publications have similarly shed new light on voting determinants in the EP by using qualitative, interview-based methods. For example, a study conducted on a sample of Danish MEPs showed national affiliation to play a much stronger role than previously acknowledged in areas such as employment, environment and agricultural policy, where MEPs seem to follow national interests rather than ideological positions (Rasmussen 2008). The same goes for another recent survey of MEPs' policy preferences, conducted in 2010, which found that the Member State of origin is a more powerful predictor of general MEPs' attitudes than the EP party group affiliation (Farrell et al. 2012). The study found that a striking $40 \%$ of variance in policy positions was explainable through MEPs' nationalities, as opposed to only $15 \%$ attributable to EP political group membership (and the remaining $45 \%$ accounted for by personal 
ideological preferences). These results are not entirely consistent with earlier research, highlighting a puzzling gap between voting behaviour and general political attitudes. In addition, they partially undermine the 'EP party cohesion' consensus and suggest that more complex dynamics might be at stake especially on salient issues, a possibility which we investigate further in this paper.

\section{The EU's Response to the Crisis: Economic Governance Reform}

The main measures adopted by the EU to reinforce its economic governance structure after the crisis and analysed in this paper are the creation of the European Stability Mechanism (ESM), the "Six-Pack" and the "Two-Pack" (O Broin 2012, European Commission 2013). This set of legislative votes does not of course represent the full population of codecision reports in this policy area, nor the full population of legislative reports in the 7th European Parliament (488), but it was chosen as a most likely case to test our hypotheses on the relevance of national factors in MEPs' voting choices. It is indeed widely acknowledged that these were indeed the most significant legislative acts in this policy area, as well as the most controversial one. The nature of the case selection process hence might create a bias in our results, which we fully recognise and discuss in the concluding section.

The European Stability Mechanism was established as a permanent firewall for euro zone Member States experiencing financial difficulty, and provides financial assistance programmes for a maximum lending capacity of $€ 500$ billion. A Member State requiring financial assistance through the ESM is subject to conditionality via a Memorandum of Understanding (MoU) and must have ratified the European Fiscal Compact. In November 2011, the Council and the European Parliament adopted a legislative package comprising five Regulations and one Directive, the Six-Pack, ${ }^{3}$ which reinforced the existing Stability and Growth Pact (SGP) in the domain of fiscal policy. The Six-Pack applies to all EU Member States, but it includes some specific rules for euro zone countries, especially regarding financial sanctions. While the SGP focused on the surveillance of Member States' budgetary deficits, its recent reform complemented the coordination procedure with a similar process for public debt levels, and put greater emphasis on prevention efforts to ensure long-term sustainability of public finances. The new EU secondary law package also created the Macroeconomic Imbalance Procedure, thereby submitting a wider spectrum of macroeconomic policies to EU level surveillance.

Another major innovation in the economic governance of the EU was the launch of the European Semester, a cycle of fiscal and economic policy coordination taking place

\footnotetext{
${ }^{3}$ Regulation (EU) No 1173/2011 of the European Parliament and of the Council of 16 November 2011 on the effective enforcement of budgetary surveillance in the euro area, Regulation (EU) No 1174/2011 of the European Parliament and of the Council of 16 November 2011 on enforcement measures to correct excessive macroeconomic imbalances in the euro area, Regulation (EU) No 1175/2011 of the European Parliament and of the Council of 16 November 2011 amending Council Regulation (EC) No 1466/97 on the strengthening of the surveillance of budgetary positions and the surveillance and coordination of economic policies, Regulation (EU) No 1176/2011 of the European Parliament and of the Council of 16 November 2011 on the prevention and correction of macroeconomic imbalances, Council Regulation (EU) No 1177/2011 of 8 November 2011 amending Regulation (EC) No $1467 / 97$ on speeding up and clarifying the implementation of the excessive deficit procedure, Directive of the Council on the requirements for budgetary frameworks of the Member States (Council Directive 2011/85/EU).
} 
during the first half of the year and embedded in the Europe 2020 strategy. Implemented for the first time in 2011, its aim is to ensure a better harmonization among fiscal and macroeconomic policies of the Member States, in the hope that synchronizing the timetables of these procedures as well as increasing EU surveillance mechanisms ensures enhanced convergence and stability in the European economies. Economic policy coordination takes place in the three areas of fiscal policy, structural reforms and macroeconomic imbalances, the latter having been acknowledged as a key factor contributing to the recent economic crisis. The European Semester places little constraint on Member States' individual choices, as EU-level guidance and countryspecific recommendations have no binding nature, thereby still giving little incentive to comply apart from reputational and peer-pressure concerns.

In May 2013, a new package of legislation including two Regulations (the TwoPack) came into force, establishing stronger surveillance mechanisms for the budgetary policies of euro area Member States. ${ }^{4}$ The Two-Pack introduced a common budgetary deadline and common budgetary rules for euro area Member States, completing the existing governance framework as this exercise of coordinated surveillance takes place in autumn. In the meanwhile, a major reform introduced by the Two-Pack consists in the European Commission's power to assess their draft budgets before domestic parliaments (by the end of November), and above all to request the concerned state to submit a revised plan if it detects severe non-compliance with SGP obligations.

\section{Data, Methodology and Hypotheses}

In order to study the voting behaviour of MEPs on economic governance issues, we use data downloaded from Votewatch.eu, the reference website to study legislators' voting behaviour in the European Parliament. The votes under analysis, discussed in the previous section, are listed in Table 1.

Each observation in the downloaded datasets refer to a single MEP's voting history and records the following variables: name of the MEP, Member State of origin, voting decision, EP party group and a binary variable signalling loyalty or rebellion to the party group. As the outcome we aim to predict is the voting decision, we use a logit model to estimate the MEP's voting behaviour based on several variables, including EP party affiliation and Member State of origin. ${ }^{5}$ The dependent variable is the voting decision; we recoded the original variable "Vote" (taking the possible values "Absent", "Abstain", "Against", "Didn't Vote", "Documented Absence" and "For") into a dichotomous variable (Vote in Favour) taking value 1 when the vote is positive and 0 in all other possible cases. In a second set of analyses, we modelled an ordered probit regression accounting for the different possible outcomes of this categorical variable, namely "Yes", "No", "Abstain" and "Else" (to group all the cases where MEPs did not

\footnotetext{
${ }^{4}$ Regulation (EU) No 472/2013 of the European Parliament and of the Council of 21 May 2013 on the strengthening of economic and budgetary surveillance of Member States in the euro area experiencing or threatened with serious difficulties with respect to their financial stability, Regulation (EU) No 473/2013 of the European Parliament and of the Council of 21 May 2013 on common provisions for monitoring and assessing draft budgetary plans and ensuring the correction of excessive deficit of the Member States in the euro area.

${ }^{5}$ We could have used a logit model as well, but we preferred probit, which is more frequently used in the related literature, in order to make results comparable with previous findings.
} 


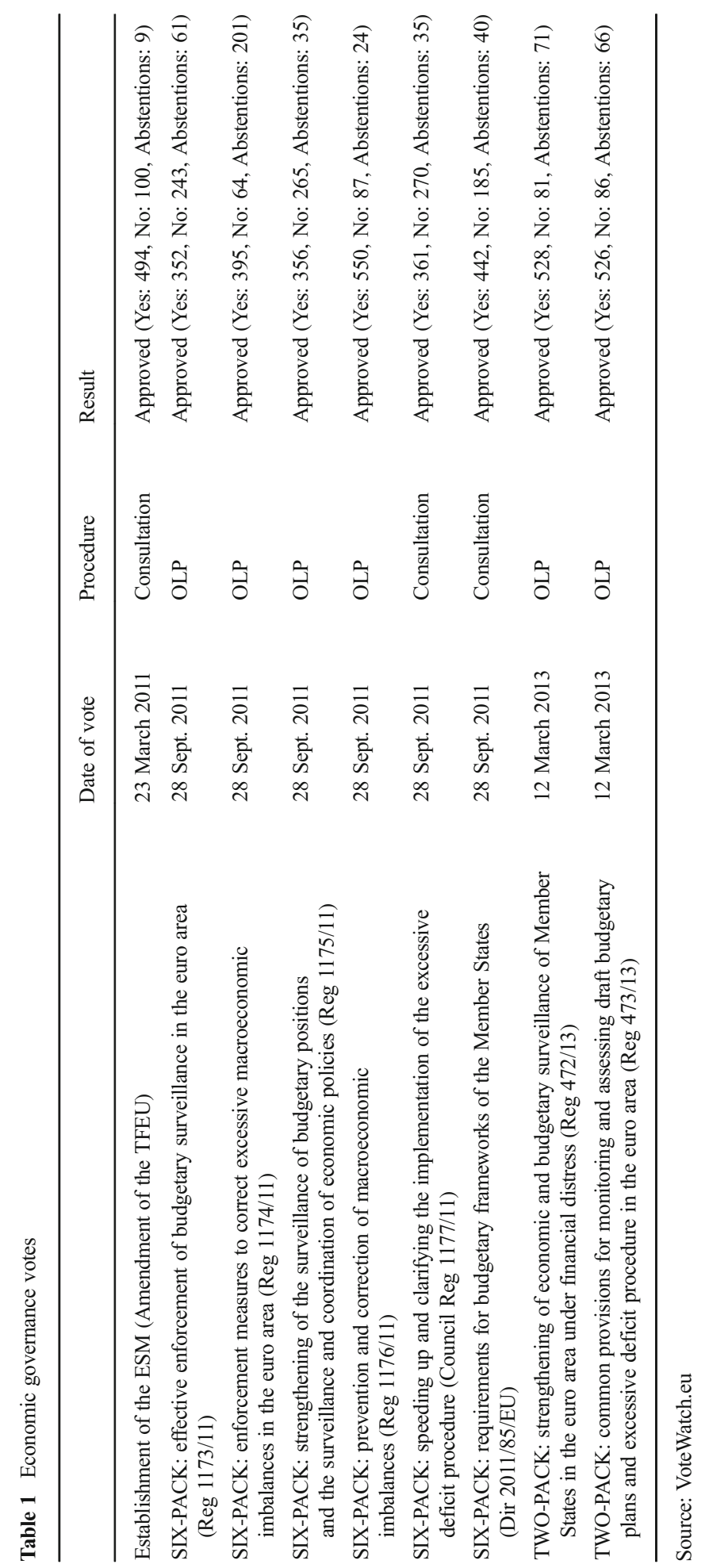


vote). We performed this second analysis led by a theoretical hypothesis that abstentions may conceal a deliberate strategic choice by MEPs, who could use this as a way to rebel against their party groups and as a signal of dissatisfaction with the proposed legislation, without going all the way and voting against it.

Table 2 shows the distribution of votes across Member States. Since the cornerstone of our analysis is the role of nationality (and country-level variables) in leading MEPs' voting choices, we started off from a descriptive visualisation of how the voting outcome and Member State are associated (Pearson's chi-square is 925.19, undoubtedly demonstrating that the two variables are not uncorrelated).

The key independent variables are "EP in Favour", "PIIGS", "Eurozone" and those related to the economic situation of the Member State of origin. "EP in Favour" is a recoding of "EP Group", which reflects the MEP's political affiliation inside the EP and takes eight possible values, corresponding to the different party groups sitting in the European Parliament (ALDE, ECR, EFD, EPP, GUE/NGL, Greens, S\&D, NonInscrits). As "EP Group" is a categorical variable with a nominal scale, we recoded it in order to signal the MEP's belonging to the party coalition supporting the vote. For each piece of legislation, we studied the distribution of "Vote in Favour" across parties in order to detect the supporting coalition of EP groups (e.g. EEP, ALDE and S\&D or EPP, ALDE and Greens/NGL), i.e. the parties where at least $80 \%$ of the affiliated Members voted in favour (see Tables 3 and 4). We then recoded the variable into a dummy taking value 1 when the MEPs is part of this "supporting coalition", which does not hold a stable pattern over all votes, and value 0 when he/she is not. The second independent variable is "PIIGS", a dummy which takes value 1 when the MEP is from Portugal, Ireland, Italy, Greece, Spain or Cyprus and 0 in all other cases; it is therefore aimed at identifying the countries particularly hit by the economic crisis and receiving or having received some form of financial assistance by the EU (with the exception of Italy). The variable "Eurozone" is a self-explanatory dummy accounting for the MEP coming from a euro area Member State.

Alongside party group and nation of origin, we aimed to assess whether economic conditions in the home country also played a part in legislators' voting decision. In order to do so, we included two additional variables in the models, namely "GDP Change" and "Unemployment Change". "GDP Change" measures the change in GDP growth from the previous year to the year when the vote takes place; thus, higher positive values signal an improvement in the country's economic conditions. "Unemployment Change" similarly measures the change in the unemployment rate from the previous year; higher values are hence a signal for the deterioration of the economic conditions in the country of the MEP. In addition, we used data on Member States' fiscal position as directly linked to the Stability and Growth Pact indicators, namely on the public debt and deficit levels, factors on which EU legislation on fiscal coordination places explicit constraints on. Finally, we controlled for the credit rating of the Member State in question.

In line with previous research findings, our first hypothesis is that EP party affiliation, operationalised through the variable "EP in Favour", is the main determinant of MEPs' voting decisions. If the EP party group cohesion is high and MEPs predominantly vote in line with ideological determinants together with party colleagues, the coefficient of "EP in Favour" should be highly significant and positive. Our next hypothesis aims to add on this baseline scenario, unchallenged in the 
Table 2 Distribution of votes by Member State

\begin{tabular}{|c|c|c|c|c|}
\hline & Yes & No & Abstain & Else \\
\hline \multirow[t]{2}{*}{ Austria } & 89 & 48 & 8 & 12 \\
\hline & $56.69 \%$ & $30.57 \%$ & $5.10 \%$ & $7.64 \%$ \\
\hline \multirow[t]{2}{*}{ Belgium } & 121 & 48 & 12 & 17 \\
\hline & $61.11 \%$ & $24.24 \%$ & $6.06 \%$ & $8.59 \%$ \\
\hline \multirow[t]{2}{*}{ Bulgaria } & 99 & 23 & 10 & 23 \\
\hline & $63.87 \%$ & $14.84 \%$ & $6.45 \%$ & $14.84 \%$ \\
\hline \multirow[t]{2}{*}{ Cyprus } & 25 & 18 & 5 & 6 \\
\hline & $46.3 \%$ & $33.33 \%$ & $9.26 \%$ & $11.11 \%$ \\
\hline \multirow[t]{2}{*}{ Czech Republic } & 51 & 79 & 51 & 17 \\
\hline & $25.76 \%$ & $39.9 \%$ & $25.76 \%$ & $8.59 \%$ \\
\hline \multirow[t]{2}{*}{ Denmark } & 61 & 37 & 9 & 10 \\
\hline & $52.14 \%$ & $31.62 \%$ & $7.69 \%$ & $8.55 \%$ \\
\hline \multirow[t]{2}{*}{ Estonia } & 51 & 0 & 0 & 3 \\
\hline & $94.44 \%$ & $0.00 \%$ & $0.00 \%$ & $5.56 \%$ \\
\hline \multirow[t]{2}{*}{ Finland } & 89 & 17 & 4 & 7 \\
\hline & $76.07 \%$ & $14.53 \%$ & $3.42 \%$ & $5.98 \%$ \\
\hline \multirow[t]{2}{*}{ France } & 409 & 149 & 21 & 73 \\
\hline & $62.73 \%$ & $22.85 \%$ & $3.22 \%$ & $11.20 \%$ \\
\hline \multirow[t]{2}{*}{ Germany } & 605 & 178 & 35 & 73 \\
\hline & $67.9 \%$ & $19.98 \%$ & $3.93 \%$ & $8.19 \%$ \\
\hline \multirow[t]{2}{*}{ Greece } & 103 & 51 & 20 & 24 \\
\hline & $52.02 \%$ & $25.76 \%$ & $10.10 \%$ & $12.12 \%$ \\
\hline \multirow[t]{2}{*}{ Hungary } & 146 & 32 & 5 & 15 \\
\hline & $73.74 \%$ & $16.16 \%$ & $2.53 \%$ & $7.58 \%$ \\
\hline \multirow[t]{2}{*}{ Ireland } & 64 & 20 & 5 & 17 \\
\hline & $60.38 \%$ & $18.87 \%$ & $4.72 \%$ & $16.04 \%$ \\
\hline \multirow[t]{2}{*}{ Italy } & 404 & 107 & 88 & 51 \\
\hline & $62.15 \%$ & $16.46 \%$ & $13.54 \%$ & $7.85 \%$ \\
\hline \multirow[t]{2}{*}{ Latvia } & 52 & 13 & 1 & 8 \\
\hline & $70.27 \%$ & $17.57 \%$ & $1.35 \%$ & $10.81 \%$ \\
\hline \multirow[t]{2}{*}{ Lithuania } & 72 & 12 & 10 & 14 \\
\hline & $66.67 \%$ & $11.11 \%$ & $9.26 \%$ & $12.96 \%$ \\
\hline \multirow[t]{2}{*}{ Luxembourg } & 43 & 7 & 3 & 1 \\
\hline & $79.63 \%$ & $12.96 \%$ & $5.56 \%$ & $1.85 \%$ \\
\hline \multirow[t]{2}{*}{ Malta } & 19 & 6 & 2 & 20 \\
\hline & $40.43 \%$ & $12.77 \%$ & $4.26 \%$ & $42.55 \%$ \\
\hline \multirow[t]{2}{*}{ Netherlands } & 158 & 47 & 10 & 37 \\
\hline & $62.70 \%$ & $18.65 \%$ & $3.97 \%$ & $14.68 \%$ \\
\hline \multirow[t]{2}{*}{ Poland } & 264 & 29 & 36 & 95 \\
\hline & $62.26 \%$ & $6.84 \%$ & $8.49 \%$ & $22.41 \%$ \\
\hline \multirow[t]{2}{*}{ Portugal } & 125 & 49 & 25 & 10 \\
\hline & $59.81 \%$ & $23.44 \%$ & $11.96 \%$ & $4.78 \%$ \\
\hline
\end{tabular}


Table 2 (continued)

\begin{tabular}{lllll}
\hline & Yes & No & Abstain & Else \\
\hline Romania & 192 & 48 & 5 & 32 \\
Slovakia & $69.31 \%$ & $17.33 \%$ & $1.81 \%$ & $11.55 \%$ \\
& 84 & 18 & 7 & 2 \\
Slovenia & $75.68 \%$ & $16.22 \%$ & $6.31 \%$ & $1.80 \%$ \\
\multirow{3}{*}{ Spain } & 71 & 9 & 20 & 7 \\
& $66.36 \%$ & $8.41 \%$ & $18.69 \%$ & $6.54 \%$ \\
Sweden & 311 & 68 & 7 & 40 \\
United Kingdom & $73.00 \%$ & $15.96 \%$ & $0.64 \%$ & $9.39 \%$ \\
& 118 & 38 & 41 & 23 \\
& $53.64 \%$ & $17.27 \%$ & $18.64 \%$ & $10.45 \%$ \\
& 160 & 225 & 102 & 91 \\
\hline
\end{tabular}

Source: VoteWatch.eu

literature, to bring national factors into MEPs' voting decision. In particular, two competing narratives result in two alternative hypotheses: hypothesis 2 is that $\hat{\beta}_{E Z}>0$, i.e. coming from the euro zone significantly enhances MEPs' likelihood of voting in favour of the proposed measure. This is likely to be the case if euro zone MEPs, whose countries of origin are to be more directly affected by the proposed reforms, wish to improve the resilience of the economic governance architecture of the euro area. In other terms, there might be an enhanced sense of 'responsibility' moving these MEPs to support a stronger coordination of economic policies significantly more than non-euro zone MEPs. Legislators from the euro zone might be more prone to blame the deficiencies in the EMU architecture especially the lack of a common fiscal policy aligned with the common monetary policy - for their countries' crisis and hence more willing to reinforce the common rules of fiscal surveillance. The confirmation of this hypothesis would signal an ever-growing differentiation between the "core" and non-euro area countries, which goes in the direction of a "two-speed" European Union: this result could be partially expected because some pieces of legislation are applicable only in the euro zone, but it would nonetheless imply that MEPs tend to consider, while voting, the consequences for their country of origin.

The alternative scenario, underlining hypothesis 3, is that MEPs from "PIIGS" countries are less likely to support the proposed economic governance reforms; in this case $\hat{\beta}_{\text {PIIGS }}<0$. This would happen if MEPs from crisis-ridden Member States, already facing tough economic conditions and financial difficulty, become wary of further strengthening fiscal rules and hence reject an economic reform inspired by the "fiscal rectitude" dogma. This scenario is coherent with political economy accounts of the crisis which underline the deepening divide between creditor and debtor Member States: we aim to assess here whether this dynamic plays out in the European Parliament as well and not only in the Council of the EU, where national interests are directly advocated and this division has been routinely reported. 


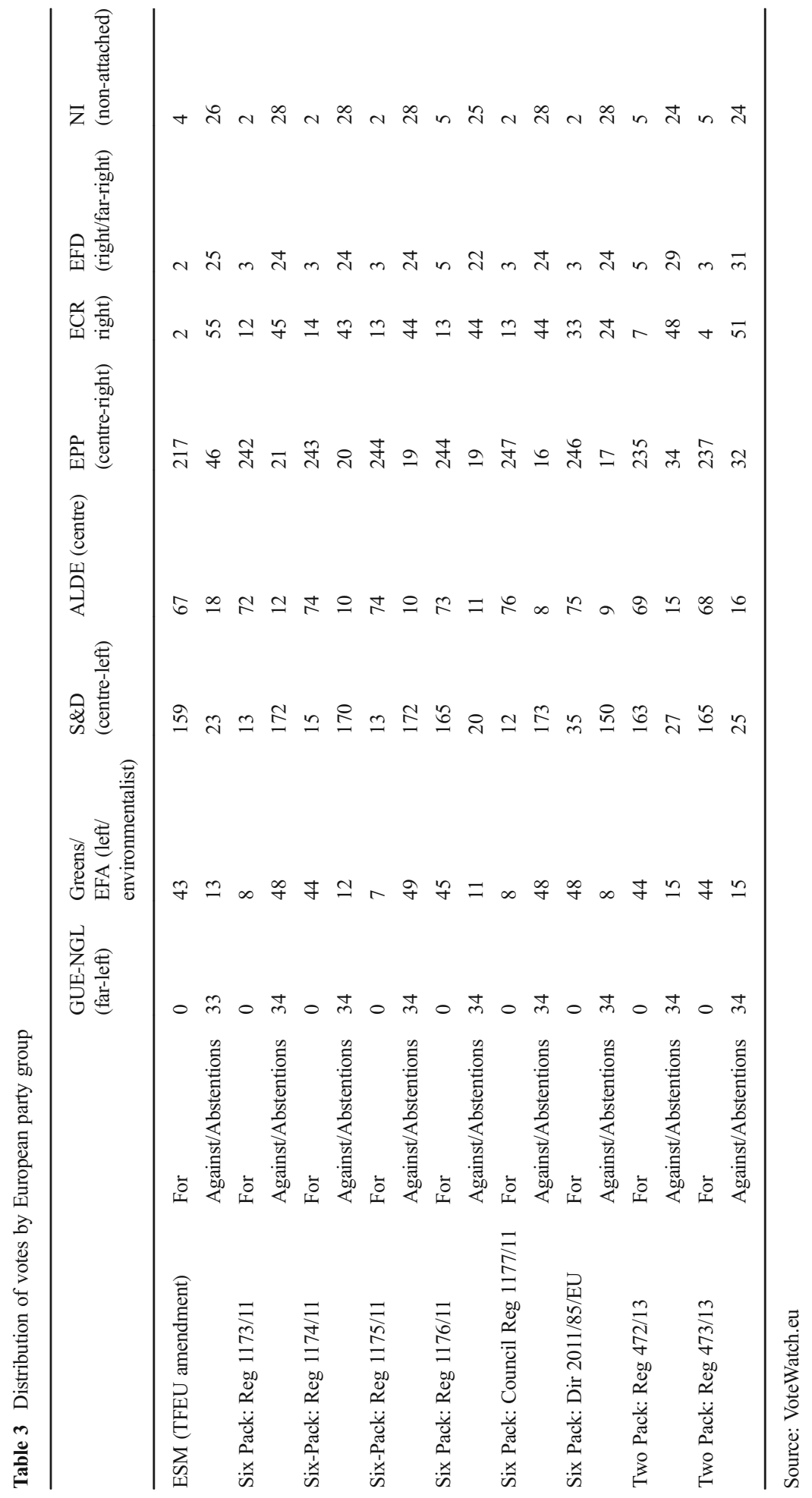




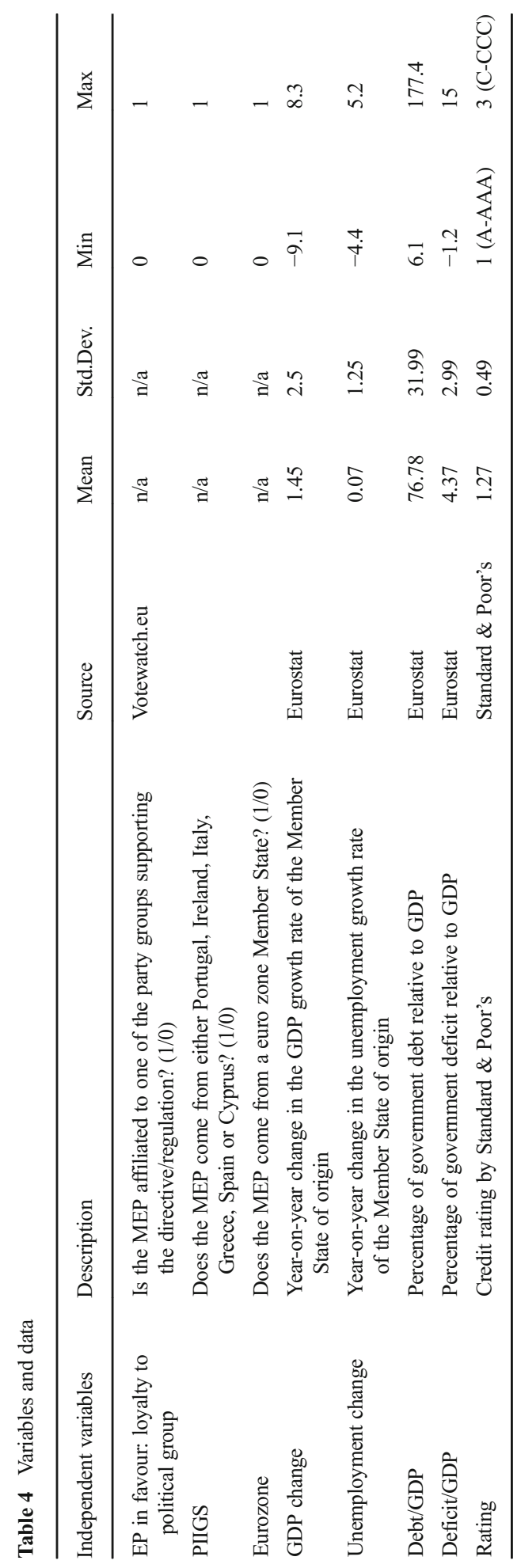


As far as the economic context is concerned, a situation of recession is expected to diminish MEPs' willingness to vote in favour of the proposed economic governance reforms, mainly because of the possibly higher "adjustment" and implementation costs of the new legislation for crisis-ridden countries. This hypothesis recalls theories of economic voting, which focus on voters' decision as driven by economic considerations, including an attribution of responsibility to the current government (the "sanctioning" model) or a selection of the most competent candidate (the "selection" model) (Bartkowska and Tiemann 2015; Okolikj and Quinlan 2016). The key difference is that economic conditions here play a role not in citizens' vote of the next government, but in legislators' vote of proposed legislation. However, there are some similarities between the selection model of economic voting and our hypothesis on MEPs' voting behavior. In other terms, forward-looking MEPs faced with worsening economic conditions in their country of origin would be less likely to support reform that goes towards strengthening fiscal policy requirements.

\section{Results}

Our analysis of the European Parliament's final votes on key crisis-related economic governance highlights some remarkable patterns. A first interesting finding we obtained by a preliminary observation of VoteWatch data is that the coalition of party groups in favour of the concerned directive/regulation was not the same on all votes (Table 2). Strengthening economic governance at the EU level did not attract the consensus of all MEPs: only ALDE and the European People's Party consistently supported the reform of the existing fiscal coordination framework. This pattern might be explained by the fact that ALDE is a centrist party group, while the European People's Party has traditonally been pro-integrationist and brings together political parties with quite conservative fiscal policy stances. This is far from surprising, since the proposed reform of the Stability and Growth Pact was criticized by most left-leaning forces: budgetary rules were deemed to be too tight and they have not been complemented by the creation of a common fiscal resource, e.g. via the issuance of Eurobonds, as advocated by some. For this reason, the S\&D group did not support any of the regulations and directives in the economic governance packages (Six-Pack and Two-Pack), with one notable exception, namely the creation of the Macroeconomic Imbalances Procedure. On the other hand, the Greens/ EFA party group showed a high degree of support for the proposed packages, possibly due to their very positive attitude towards stronger EU integration. This varying pattern of support for the proposed economic governance measures does not reflect only the different degree of consensus regarding the single initiatives, it also mirrors the growing politicization of the European Parliament (Kreppel 2000; Hix and Bartolini 2006).

Logistic regressions were run on the two pooled clusters of economic governance votes to test our hypotheses. First, we find confirmation of the traditional results in the scholarly literature on voting behaviour in the European Parliament, i.e. that the primary factor influencing a legislator's decision to vote in favour or against a proposed measure is his/her EP party affiliation. This is demonstrated by the high and positive coefficient of the variable "EP in Favour", which is highly significant across all estimated models (Table 5). Moreover, Hypothesis 2 is also confirmed: MEPs from the euro zone are significantly more likely to support economic governance reform, 


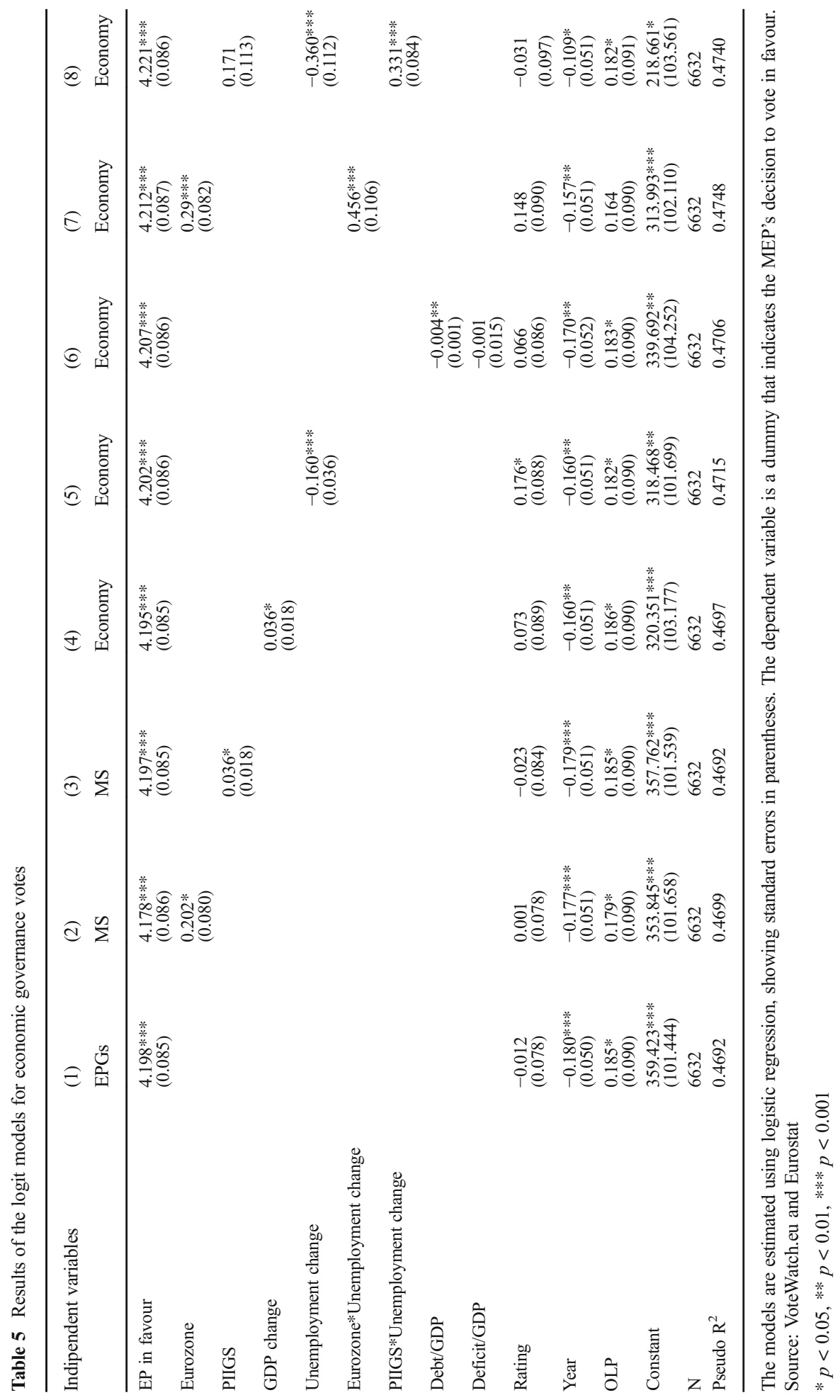


even controlling for EP party affiliation. The coefficient, although not particularly high, is significant at the $95 \%$ confidence level. On the other hand and contrary to our expectations, coming from a crisis-ridden country (PIIGS) seems to affect MEPs' voting behaviour in the opposite direction than expected: while the coefficient is not of a high magnitude, it is positive and statistically significant, thus implying MEPs from crisis-ridden countries are also more likely to vote in favour. This result, although surprising, might be explained by the fact that PIIGS countries are actually all Eurozone Member States and the two groupings are hence overlapping. Hypothesis 3 is not confirmed: MEPs from crisis-ridden countries are not less likely than MEPs from other Member States to vote in favour of economic governance reform.

Turning to the role played by the economic context of MEPs' Member States of origin, our results find support for the effect of both GDP and unemployment rates on their voting decisions on economic governance reform. The coefficients on both "GDP Change" and "Unemployment Change" (included in alternative model specifications due to multicollinearity issues) are both significant and in the expected direction. MEPs facing a worsening of the economic conditions in their countries are less likely to vote in favour of the proposed reform, centred on a tightening of common fiscal rules. Thus, they are forward-looking and anticipate future adjustment costs for their home economies. This result is particularly interesting since the role of economic factors in MEPs' vote choices has not been explored in the literature so far, yet our findings suggest this is an interesting path to explore. Similarly, the coefficient on the public debt position of the country of origin is also significant and positive (higher debt/GDP levels make MEPs less likely to vote in favour), while the coefficient on deficit positions is not. Another interesting result is the fact that the percentage of positive votes was generally higher in 2013 than in 2011, as signalled by the significant and positive coefficient on the year dummy. Similarly, the legislative procedure seems to matter somewhat, with MEPs more likely to cast a positive vote when under the ordinary legislative procedure than in the case of other procedures (in this case, consultation). Lastly, the credit rating of the country of origin does not make any difference on MEPs' voting behaviour.

The figures below show the marginal effect on unemployment growth in the MEPs' countries of origin: as the unemployment rate rises, MEPs are significantly less likely to vote in favour of the proposed legislation. The same happens for the GDP variable: as GPD rises and the economic conditions get better, MEPs are more likely to vote in favour of legislation on fiscal integration (Figs. 1 and 2).

In models (7) and (8), we added interaction terms to investigate whether these macro-economic variables have a differential impact on euro zone or PIIGS MEPs; we focused on unemployment levels since we found it to be a stronger predictor. Here, results indeed show that the effect of unemployment change is highly significant for non-eurozone and non-PIIGS countries, as we can see in Figs. 3 and 4. More specifically, for Eurozone MEPs a worsening of the unemployment conditions only has a very small effect on their probability to vote in favour, whereas the effect of this variable is massive for MEPs coming from non-eurozone countries. A similar pattern is detected regarding PIIGS versus non-PIIGS countries, as the effect of a change in unemployment levels is only significant for MEPs not coming from crisis-affected Member States. These results certainly deserve some additional theoretical investigation in further research. 

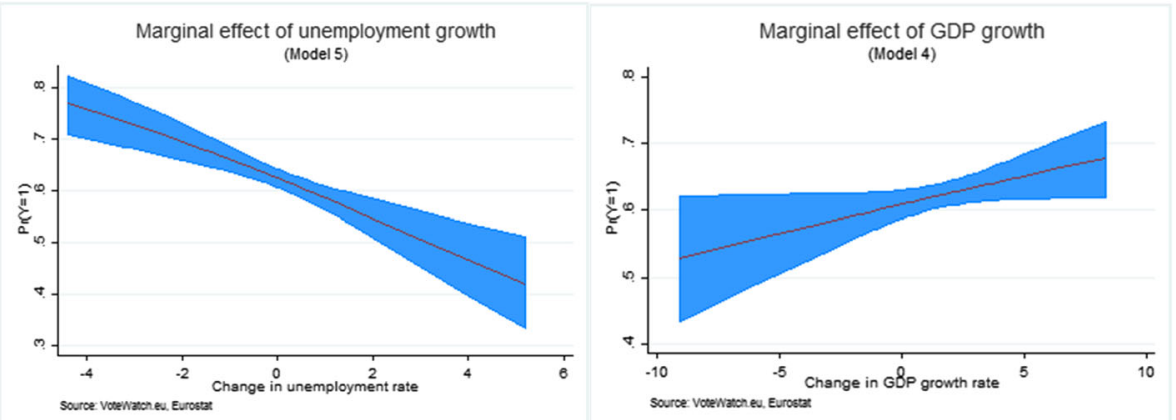

Figs. 1 and 2 Marginal effects of unemployment growth and GDP growth

In a second part of the analysis, we estimated ordered probit models in order to account for a finer grained vote choice, namely taking into account not only the decision to vote in favour but also that of casting a negative vote and to abstain. As shown in Table 6, the model fits decrease quite remarkably, while the size and significance of the coefficients is overall very similar (although in the opposite direction as the highest category of the dependent variable used here is the decision to abstain from the vote). There are however a few differences, like the fact that here GDP change is a much stronger predictor, as is the origin from a PIIGS country; hence, MEPs from crisis-ridden Member States are more likely to abstain from the vote, and also more likely to vote against than vote in favour of proposed legislation.

As a final check, we estimated all the models separately for each of the voting resolutions and each of the countries. While estimating vote choice on some of the crisis-ridden countries separately did lower the number of observations (particularly for small Member States such as Cyprus), thus leading in higher standard errors and fewer significant coefficients, overall our results are robust to these alternative specifications.

\section{Conclusions}

This article aimed to assess MEPs' voting behaviour in the arena of crisis-driven economic governance reform at EU level. Our expectation was that a range of factors was relevant alongside political party affiliation in shaping MEPs' voting decisions on these sensitive
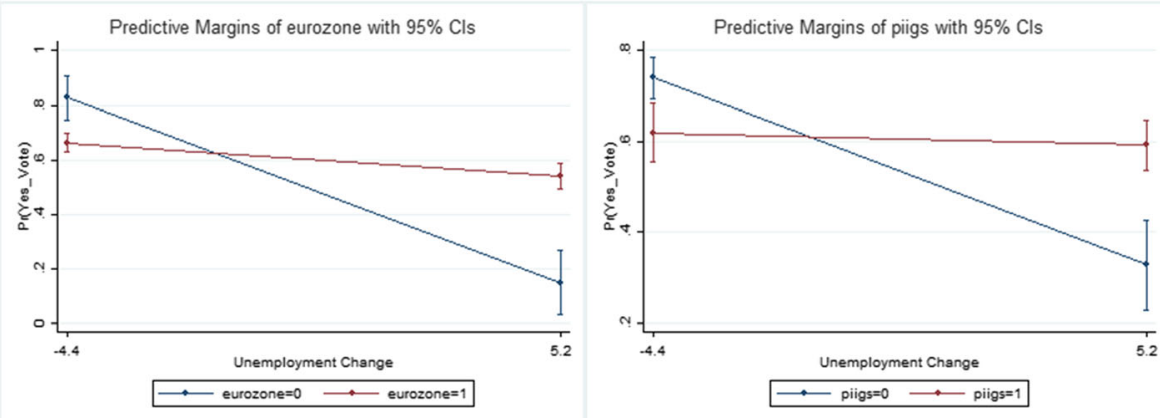

Figs. 3 and 4 Marginal effect of Unemployment according to MS of origin 


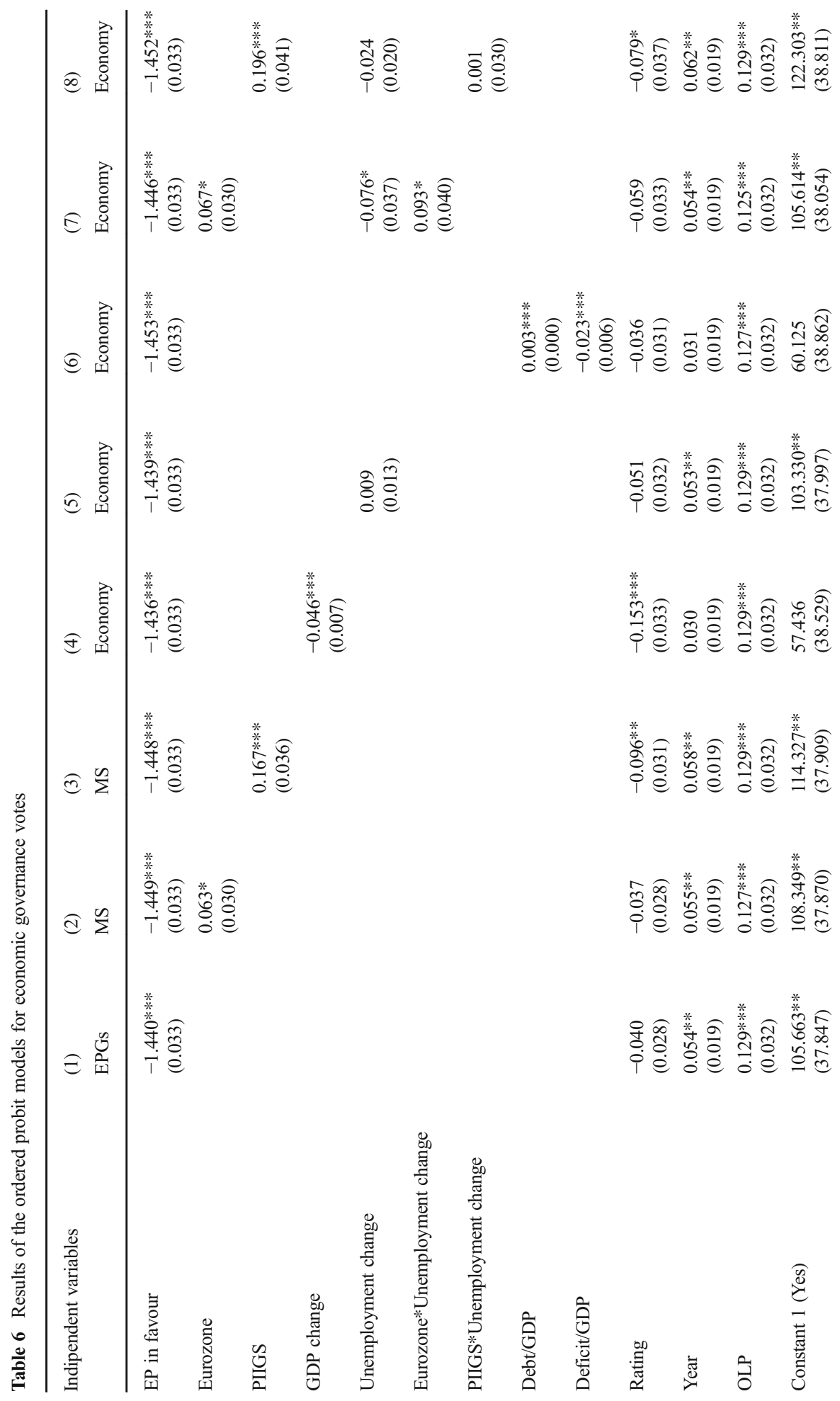




$$
\text { 五 }
$$


issues, particularly in a context which experienced a resurgence of nationalist feelings on some crisis-management choices. More specifically, we expected MEPs' national origins and home countries' economic conditions to create possible cleavages and determine distinctive voting patterns, especially on some delicate matters.

In accordance with the established literature on voting behaviour in the European Parliament, the quantitative analysis showed the most powerful predictor of one MEP's decision to vote in favour to be her EP party group. Nevertheless, a second noteworthy finding is the peculiar role played by the economic situation under the form of GDP and unemployment indicators in the MEP's country of origin. A deterioration in the national employment situation or GDP growth rate had a negative effect on the legislators' probability to support the new EU economic governance structure: when the unemployment level increased or the GDP growth rate decreased, MEPs were less likely to cast a positive vote on the proposed reform of economic governance. However, these macroeconomic indicators have a differential impact on MEPs from different sets of countries, and worsening economic conditions seem to have mattered the most for MEPs not coming from either the euro zone or PIIGS countries. Whereas these partially unexplained findings deserve some further theoretical investigation, including these variables in the analysis shows that national factors are indeed relevant in determining MEPs' behaviour, even when controlling for EP party affiliation.

In spite of the limited nature of the study and the peculiar nature of votes chosen, our findings add some interesting insights to the research on voting behaviour inside the European Parliament. Intra-party voting cohesion has been on the rise for several decades and party affiliation is shown to have played a fundamental role in our sample of votes, in line with existing literature. While the generalizability of this study might be limited - we chose a sample of highly salient and consequential votes - there are some lessons to be learnt on the role of national factors in predicting MEPs' behavior, at least on particularly controversial and non-routine issues. Our findings for the economic context shed some new light on previous research, and suggest a possible enlargement of the analysis to a more comprehensive group of votes, both in the economic and financial realm as in other policy areas. These findings could also be related to the results in a similar area of study on the European Parliament, which looks at how legislative reports are allocated among committee members. Investigating factors affecting rapporteurship allocation, several scholars have found that national factors play a role in these choices too (Kaeding 2004; Hurka and Kaeding 2012). Context might be more crucial than usually believed in this strand of the literature, and we should explore this avenue further.

Open Access This article is distributed under the terms of the Creative Commons Attribution 4.0 International License (http://creativecommons.org/licenses/by/4.0/), which permits unrestricted use, distribution, and reproduction in any medium, provided you give appropriate credit to the original author(s) and the source, provide a link to the Creative Commons license, and indicate if changes were made.

\section{References}

Attinà F (1990) The Voting Behaviour of the European Parliament Members and the Problem of Europarties. Eur J Polit Res 18(5):557-579

Bartkowska M, Tiemann G (2015) The Impact of Economic Perceptions on Voting Behaviour in European Parliament Elections. J Common Mark Stud 53(2):201-2017

Bressanelli E (2012) National parties and group membership in the European Parliament: ideology or pragmatism? J Eur Publ Policy 19(5):737-754 
Carrubba CJ, Gabel M, Murrah L, Clough R, Montgomery E, Schambach R (2004) A Second Look at Legislative Behaviour in the European Parliament, Political Science Series. Institute for Advanced Studies, Vienna

Carrubba CJ, Gabel M, Murrah L, Clough R, Montgomery E, Schambach R (2006) Off the record: unrecorded legislative votes, selection bias and roll-call vote analysis. Br J Polit Sci 36(4):691-704

Cicchi L (2013) "The Logics of Voting Behaviour in the European Parliament: new insights on party groups membership and national affiliation as determinants of vote", presented at. SISP 2013

European Commission (2013) 'Two-Pack' enters into force, completing budgetary surveillance cycle and further improving economic governance for the euro area, MEMO/13/457, 27 May 2013

Farrell D, Hix S, Scully R (2012) National or European Parliamentarians? Evidence from a New Survey of the Members of the European Parliament. J Common Mark Stud 50(4):670-683

Gische E (2007) Modeling Voting Behaviour in the European Parliament on Foreign Policy Issues: Analyzing the Tension between Party Affiliation and National Identity. http://www.stanford. edu/dept/publicpolicy/programs/Honors_Theses/Theses_2007/Gische.pdf

Hix S (2001) Legislative Behaviour and Party Competition in the European Parliament: An Application of Nominate to the EU. J Common Mark Stud 39(4):663-688

Hix S (2002) Parliamentary Behaviour with Two Principals: Preferences, Parties, and Voting in the European Parliament. Am J Polit Sci 46(3):688-698

Hix S, Bartolini S (2006) Politics: the Right or the Wrong Sort of Medicine for the EU?, Notre Europe, Policy Paper No. 19, March 2006. http://www.notre-europe.eu/media/policypaper19-en.pdf?pdf=ok

Hix S, Høyland B (2011) The Political System of the European Union, 3rd edn. Palgrave Macmillan, London

Hix S, Noury A (2009) After Enlargement: Voting Patterns in the Sixth European Parliament. Legis Stud Q 34(2):159-174

Hix S, Noury A, Roland G (2006) Dimensions of Politics in the European Parliament. Am J Polit Sci 50(2): 494-511

Hix S, Noury A, Roland G (2013) Is there a strategic selection bias in roll-call votes? Evidence from the European Parliament, Working Paper, May 2013. http://personal.1se.ac.uk/hix/Working Papers/Selection_EP_3May2013.pdf

Høyland B (2010) Procedural and party effects in European Parliament roll-call votes. Eur Union Polit 11(4): $597-613$

Hurka S, Kaeding M (2012) Report allocation in the European Parliament after eastern enlargement. J Eur Publ Policy 19(4):512-529

Kaeding M (2004) Rapporteurship allocation in the European Parliament. Eur Union Polit 5(3):353-371

Kang Y-D (2013) European Affiliations or National Interests? An Analysis of Voting Patterns on Trade Policy in European Parliament, Korea Institute for International Economic Policy, KIEP working paper 13-07

Kreppel A (2000) Rules, Ideology and Coalition Formation in the European Parliament. Past, Present and Future. Eur Union Polit 1(3):340-362

Kreppel A, Tsebelis G (1999) Coalition formation in the European Parliament. Comp Pol Stud 32(8):933-966

Levitt SD (1996) How Do Senators Vote? Disentangling the Role of Voter Preferences, Party Affiliation, and Senator Ideology. Am Econ Rev 86(3):425-441

McElroy G (2007) Legislative Politics as Normal?: Voting Behaviour and Beyond in the European Parliament. Eur Union Polit 8(3):433-448

McElroy G, Benoit K (2011) Policy positioning in the European Parliament. Eur Union Polit 13(1):150-167

O Broin P (2012) The Euro Crisis: EU Financial Reform and the European Parliament, Working Paper, Institute for International and European Affairs, available at http://www.iiea.com/publications/the-eurocrisis-eu-financial-reform-and-the-european-parliament

Okolikj M, Quinlan S (2016) Context Matters: Economic Voting in the 2009 and 2014 European Parliament Elections. Polit Gov 4(1):145-166

Rasmussen MK (2008) Another Side of the Story: A Qualitative Case Study of Voting Behaviour in the European Parliament. Politics 28(1):11-18

Ringe N (2010) Who Decides, and How? Preferences, Uncertainty, and Policy Choice in the European Parliament. Oxford University Press, Oxford 